\title{
Pengembangan Krim Pewarna Rambut Permanen Mengandung Ekstrak Daun Ketapang (Terminalia catappa L) dan Ekstrak Daun Jambu Biji (Psidium guajava L)
}

\section{Development of Permanent Hair Dye Cream Containing Ketapang (Terminalia catappa L.) and Guava (Psidium guajava L) Leaves Extracts}

\author{
Erny Marleny Effendy*, Shelly Taurhesia, Anny Victor Purba \\ Program Magister Ilmu Kefarmasian, Fakultas Farmasi, Universitas Pancasila \\ Jl. Raya Lenteng Agung No. 56-80, RT 1/RW 3, Srengseng Sawah, \\ Jagakarsa 12630, Jakarta Selatan, Indonesia \\ *Corresponding author email: erny_ef@yahoo.com
}

Received 11-11-2019 Accepted 12-12-2019 Available online 30-12-2019

\begin{abstract}
ABSTRAK
Perubahan warna rambut menjadi putih pada usia lanjut sering kurang disukai. Keanekaragaman hayati Indonesia mendorong peneliti untuk melakukan pengembangan pewarna rambut dari ekstrak daun ketapang dan daun jambu biji. Ekstrak daun jambu biji mengandung pyrogallol yang berfungsi sebagai pembangkit warna dan ekstrak daun ketapang mengandung punicalagin sebagai polyphenol yang berfungsi sebagai pewarna. Kedua bahan ini diformulasikan dalam sediaan krim dengan tujuan memudahkan dalam pemakaian. Pada penelitian ini digunakan ekstrak daun jambu biji dengan konsentrasi $12,5 \%$ dan ekstrak daun ketapang dengan variasi konsentrasi 10; 12,5 ; dan $15 \%$. Penambahan logam tembaga sulfat $1 \%$ (F5B) terhadap formula optimal menjadikan warna lebih tua. Pengujian warna pada pewarna rambut dengan penambahan logam menggunakan alat kromameter memberikan warna merah dengan nilai a $(9,00)$ warna biru dengan nilai $b(3,37)$ warna yang terrefleksi adalah coklat tua, sedangkan pewarna rambut tanpa penambahan logam memberikan warna merah dengan nilai a $(7,36)$, warna biru dengan nilai b $(16,96)$ warna yang terrefleksikan adalah coklat muda. Hasil uji keamanan menggunakan tiga ekor kelinci dengan metode uji iritasi akut dermal dengan indek iritasi nol (0) dinyatakan aman serta tidak mengiritasi.
\end{abstract}

Kata kunci: daun, ekstrak, krim, pewarna rambut.

\section{ABSTRACT}

People may lose their confidence when they start having grey hair. Development of permanent hair dyes from guava and tropical almond leaves extracts is feasible, that 
guava leaves contain pyrogallol as a color developer and tropical almond leaves contain polyphenol as a colorant. Both plant materials were extracted and formulated into cream preparation for an easier application. In this study, guava leaves extract was $12.5 \%$, while tropical almond leaves extract was varied, they were 10, 12.5, and 15\%. The addition of $1 \%$ cuprum sulfate (F5B) into the formula contributed to the darker color. The formulae with the addition of metal showed a dark brown color that $a$ and $b$ values were 9.00 (indicating red color) and 13.37 (indicating blue color), respectively, while formulae without the addition of metal showed a light brown color with $a$ and $b$ values were 7.36 (indicating red) and 16.96 (indicating brown). The result of acute dermal irritation test on Australian White rabbits showed the formulae were non-irritant with an index of zero (0).

Key words: cream, extract, hair color, leaves.

\section{Pendahuluan}

Warna rambut akan berubah menjadi putih, bila mencapai usia lanjut dan ini sering kurang disukai keberadaannya. Rambut menjadi putih dapat disebabkan karena hilangnya aktivitas enzim dalam sel pigmen dan bisa juga akibat faktor keturunan. Warna rambut dapat diubah-ubah secara buatan dengan menggunakan cat rambut, di Indonesia disebut juga dengan semir rambut, yaitu mengecat rambut putih (uban) agar tetap nampak berwarna. Warna rambut pada manusia bermacam-macam, ada yang berwarna hitam, merah kecokelatan, cokelat, keemasan atau pirang dan sebagainya (Thom dan Evans, 2006).

Pewarna sintetik secara umum diketahui dapat menyebabkan dermatitis dan beberapa masalah lainnya. Sehingga peneliti mencari alternatif pewarna rambut yang berasal dari herbal untuk menggantikan pewarna sintetik. Hasil wawancara dari 200 perempuan, 149 $(74,5 \%)$ mengatakan menggunakan pewarna rambut. Alasan mereka bervariasi seperti untuk menutupi rambut uban sebanyak 35 perempuan (23,5\%), untuk memperbaiki penampilan sebanyak 36 perempuan $(24,2 \%)$, dan mengikuti trends sebanyak 78 perempuan $(52,3 \%)$. Sebanyak $38,9 \%$ memilih pewarna herbal karena dipercaya lebih aman dibanding pewarna sintetik (Dr.Duke's Phytochemical and Ethnobotanical Database, 1992).

Kekayaan alam Indonesia berupa flora yang beragam merupakan potensi alam yang dapat dikembangkan, salah satunya potensi sebagai pewarna alami untuk rambut yaitu berasal dari daun ketapang (Terminalia catappa L). Daun ketapang sudah digunakan sebagai alternatif pengobatan secara luas terutama pada pengobatan dermatitis, hepatitis, nyeri, dan diabetes. Daun ketapang segar di negara-negara tetangga lainnya sudah digunakan sebagai pewarna makanan atau pewarna kain (Satyanand et al., 2012). Punicalagin, suatu ellagitanin, merupakan senyawa polifenol. Punicalagin terdapat dalam daun 
ketapang sebagai senyawa utama dalam bentuk alpha dan beta. Punicalagin larut dalam air dan mempunyai bioavailability tinggi (Chansue dan Assawawongkasem, 2008).

Daun jambu biji (Psidium guajava L.) mengandung pirogalol yang bersifat sebagai reduktor (mudah teroksidasi). Dalam bentuk larutan akan menjadi warna gelap jika terkena udara. Jika pemakaiannya dicampur dengan zat warna yang berasal dari tumbuhtumbuhan, pirogalol berfungsi sebagai zat pembangkit warna dan dikombinasikan dengan pewarna logam lain. Ini bertujuan untuk mendapatkan keuntungan agar zat warna dapat menempel lebih kuat lagi pada rambut dibandingkan pada saat sebelum dicampur. Pirogalol diizinkan digunakan sebagai zat pembangkit warna kombinasi dari ekstrak kedua tanaman ini diharapkan akan memberikan kerja optimal sehingga pewarnaan menjadi lebih kuat.

\section{Metode Penelitian}

Alat dan Bahan

Daun ketapang diambil di Kawasan Industri Pulogadung berumur 5 tahun dengan diameter batang $70 \mathrm{~cm}$. Daun jambu biji diambil di daerah Cibinong. Bahan-bahan lainnya adalah carbomer tipe 940 standar kosmetik (Asland, USA), sodium laurileter sulfat standar kosmetik (BASF, German), cocamide DEA standar kosmetik (BASF, German), setil alkohol standar kosmetik (Croda, German), glyceryl monostearate standar kosmetik (Croda, German), $\mathrm{Na}_{2}$ EDTA (E-Merck), amonium hidroksida $20 \%$ (E-Merck), sodium pirophosphate (E-Merck), sodium sulfit (E-Merck), hidrogen peroksida 30\% (E-Merck), phosporic acid (E-Merck), asam sulfat (p) (E-Merck), feri klorida 5\% (E-Merck), $\mathrm{KOH} 5 \%$ (E-Merck), $\mathrm{NaOH} 5 \%$ standar emprove (E-Merck), etanol 96\% standar teknis (Karsavicta, Indonesia).

$\mathrm{pH}$ meter tipe seven easy (Mettler Toledo, German), kromameter tipe CR 300 (Minolta, Jepang), timbangan tipe C-300 (Chio), rotary evaporator tipe OV 05 TS (Janke \& Junke), hewan uji kelinci New Zealand white sehat dengan berat sekitar 2,5-3,5 $\mathrm{kg}$ dan diketahui galurnya.

Jalannya Penelitian

1. Pembuatan ekstrak daun ketapang dan daun jambu biji

Simplisia daun ketapang dan daun jambu biji yang telah dideterminasi di Herbarium Bogoriensis, LIPI Cibinong, diekstraksi masing-masing dengan cara maserasi dengan pelarut etanol $70 \%$, kemudian disaring dengan kertas saring Whatman no 40. Maserat dikentalkan dengan alat rotary evaporator pada suhu $40{ }^{\circ} \mathrm{C}$, sehingga didapat 2 ekstrak kental yaitu ekstrak daun ketapang dan ekstrak daun jambu biji.

2. Metode pemeriksaan mutu ekstrak daun ketapang dan ekstrak daun jambu biji

Kadar sari yang larut dalam air dan larut dalam etanol

Ekstrak daun ketapang dan ekstrak daun jambu bji masing- 
masing ditimbang lebih kurang $5 \mathrm{~g}$ ekstrak yang telah dikeringkan di udara. Untuk pengujian sari larut dalam air masing-masing ekstrak dimasukkan ke dalam $100 \mathrm{ml}$ air jenuh kloroform dan untuk pengujian sari larut dalam etanol masing-masing ekstrak dimasukkan ke dalam $100 \mathrm{ml}$ air jenuh etanol (95\%). Ekstrak dikocok selama 6 jam, kemudian dibiarkan selama 18 jam. Selanjutnya ekstrak disaring, dipipet $20 \mathrm{ml}$ filtrat, lalu diuapkan hingga kering dalam cawan porselen yang telah dipanaskan pada suhu $105{ }^{\circ} \mathrm{C}$, dan ditara. Sisa ekstrak dpanaskan pada suhu $105{ }^{\circ} \mathrm{C}$ hingga botol tetap. Kadar dalam persen sari yang larut dalam air dihitung (Depkes RI, 1995; Depkes RI, 2000). Perhitungan kadar sari larut air dapat dilihat pada Persamaan 1.

$$
\% \text { sari larut air }=\frac{W_{2}-W_{0}}{W_{1}} \times 100 \%
$$

Keterangan:

$\mathrm{W}_{0}=$ bobot cawan kosong

$\mathrm{W}_{1}=$ bobot ekstrak kental

$\mathrm{W}_{2}=$ bobot cawan dan residu di oven

Kadar abu

Masing-masing ekstrak dilakukan pengujian kadar abu. Sebanyak $1 \mathrm{~g}$ ekstrak ditimbang $\left(W_{1}\right)$, dimasukkan dalam krus silikat yang sebelumnya telah dipijarkan dan ditars $\left(\mathrm{W}_{0}\right)$. Ekstrak dipijarkan dengan menggunakan tanur dengan suhu 600 ${ }^{0} \mathrm{C}$, hingga arang habis. Kemudian ditimbang sampai bobot tetap $\left(\mathrm{W}_{2}\right)$ (Depkes RI, 2000). Perhitungan kadar abu total dapat dilihat pada Persamaan 2.

$$
\% \text { kadar abu total }=\frac{W_{2}-W_{0}}{W_{1}} \times 100 \%
$$

Keterangan:

$\mathrm{W}_{0}=$ bobot cawan kosong

$\mathrm{W}_{1}=$ bobot ekstrak awal

$\mathrm{W}_{2}$ = bobot cawan+ekstrak setelah diabukan

Kadar abu yang tidak larut dalam asam

Masing-masing ekstrak dilakukan pengujian dengan cara abu yang diperoleh pada penetapan kadar abu total dididihkan dengan $25 \mathrm{ml}$ asam sulfat encer selama 5 menit. Bagian yang tidak larut asam dikumpulkan, kemudian disaring dengan kertas saring bebas abu dan residunya 
dibilas dengan air panas. Abu yang tersaring dan kertas saringnya dimasukkan kembali dalam krus silikat yang sama. Setelah itu ekstrak dipijar dengan menggunakan tanur, dengan suhu dinaikkan secara bertahap hingga $600 \pm 25{ }^{\circ} \mathrm{C}$, hingga arang habis. Kemudian abu ditimbang sampai bobot tetap $\left(\mathrm{W}_{2}\right)$ (Depkes RI, 2000). Rumus perhitungan dapat dilihat pada Persamaan 3.

$$
\%=\frac{W_{2}-(C x 0,0076)}{W_{1}} x 100 \%
$$

Keterangan:

WO = bobot cawan kosong

C = bobot kertas saring

$\mathrm{W}_{1}=$ bobot esktrak awal

$\mathrm{W}_{2}$ = bobot cawan+abu yang tidak larut asam

$\underline{\text { Kadar air }}$

Alat disiapkan dengan tahapan berikut. Alat disambungkan pada sumber listrik. Botol karl fischer dan botol metanol terisi. Metanol dimasukkan ke dalam labu titrasi dengan menekan tombol "in" yang terletak di samping labu titrasi hingga elektroda double platina terendam. Tombol nomer tiga (bertuliskan "user meth") ditekan hingga muncul "user method>recall method") lalu dienter.

$$
K F=\frac{2 x 18,02 x W}{230,06 x V t}
$$

$$
\% \text { Kadar air }=\frac{F x V t}{W} \times 100
$$

Keterangan:

$\mathrm{W}=$ berat sampel awal

$\mathrm{KF}=$ konstanta faktor

$\mathrm{Vt}=$ volume titran 
3. Metode penapisan fitokimia ekstrak daun ketapang dan ekstrak daun jambu biji

Masing-masing ekstrak dilakukan uji flavonoid, saponin, tannin, dan kuinon. Selain itu ekstrak juga dilakukan uji fenolik, alkaloid, steroid/terpenoid, dan uji kumarin.

Uji flavonoid, saponin, tanin, dan kuinon

Sebanyak 0,5 g fraksi aktif dilarutkan dalam $10 \mathrm{ml}$ air dan dipanaskan di atas penangas air kemudian larutan tersebut dibagi ke dalam empat tabung. Pada tabung pertama, sebanyak lebih kurang 100 mg serbuk magnesium dimasukkan ke dalam tabung lalu ditambah $1 \mathrm{ml} \mathrm{HCl}$ pekat dan $3 \mathrm{ml}$ amil alkohol, dikocok kuat dan dibiarkan memisah. Warna merah, kuning, jingga pada lapisan amil alkohol menunjukkan adanya flavonoid. Pada tabung kedua dikocok secara vertikal selama 10 detik, maka akan terbentuk busa stabil, dibiarkan selama 10 menit, ditambahkan 1 tetes $\mathrm{HCl} 1 \%$, Jika busa tidak hilang maka menunjukkan adanya saponin. Pada tabung ketiga ditambahkan beberapa tetes $\mathrm{NaOH} 1 \mathrm{~N}$, adanya larutan warna merah menunjukkan adanya kuinon. Pada tabung keempat ditambahkan beberapa tetes larutan $\mathrm{FeCl}_{3} 1 \%$, terbentuknya larutan warna biru tua atau hijau kehitaman menunjukkan adanya tanin.

Uji alkaloid

Sebanyak 0,5 g fraksi aktif ditambah $5 \mathrm{ml} \mathrm{HCl}$ 10\%, dikocok, dan ditambah $5 \mathrm{ml}$ larutan amoniak 10\%.
Larutan diekstraksi dengan kloroform dan diuapkan. Residu sisa penguapan ditambah $1,5 \mathrm{ml} \mathrm{HCl} 2 \%$ dan dibagi dalam dua tabung. Tabung pertama ditambahkan 2-3 tetes pereaksi Mayer, Jika terbentuk endapan putih kekuningan menunjukkan adanya alkaloid. Tabung kedua ditambah 2-3 tetes pereaksi Dragendorff, jika terbentuk endapan merah bata menunjukkan adanya alkaloid.

Uji fenolik

Identifikasi adanya senyawa fenolik dalam suatu cuplikan dapat dilakukan dengan pereaksi $\mathrm{FeCl}_{3}$ 1\% dalam etanol. Adanya senyawa fenolik ditunjukkan oleh timbulnya warna hijau, merah ungu, biru, atau hitam yang kuat.

Uji steroid/terpenoid

Ekstrak etil asetat dimaserasi dengan beberapa $\mathrm{mL}$ eter lalu dipindahkan ke dalam dropple plate untuk diuji dengan pereaksi Liebermann Bouchard (2 tetes asam asetat anhidrat dan 1 tetes asam sulfat pekat). Residu yang tidak larut dalam eter selanjutnya dihidrolisis dengan $\mathrm{HCl} 2 \mathrm{~N}$ di atas penangas air kemudian dilarutkan dalam eter dan diuji kembali dengan pereaksi Liebermann Bouchard. Terbentuknya warna biru atau hijau menunjukkan adanya steroid dan warna merah adanya terpenoid.

Uji kumarin

Sebanyak 0,5 gram fraksi aktif ditambahkan $10 \mathrm{ml}$ eter, setelah dingin lalu disaring. Filtrat diuapkan, ditambahkan $10 \mathrm{ml}$ air panas dan 
didinginkan, kemudian ditambahkan $0,5 \mathrm{ml}$ larutan amoniak 10\%. Adanya fluoresensi hijau atau biru pada sinar UV menunjukkan adanya kumarin.

4. Pembuatan krim pewarna rambut

Disodium EDTA dilarutkan dalam $10 \mathrm{ml}$ purified water, diaduk sampai larut, ditambahkan sodium sulfite, diaduk sampai larut, ditambahkan phenoxy ethanol, diaduk homogen. Selanjutnya campuran bahan ditambahkan carbomer, diaduk sampai mengembang, ditambahkan amonium hidroksida 20\%, diaduk homogen, ditambahkan sodium lauryl ether sulfate, dan diaduk homogen. Dalam wadah terpisah, didispersikan ekstrak dalam $10 \mathrm{ml}$ purified water, diaduk sampai homogen, dimasukkan ekstrak ke dalam basis, diaduk homogen, ditambahkan cocamide DEA, diaduk homogen, digenapkan massa dengan purified water sampai 100 gram. Formula pewarna rambut dapat dilihat pada Tabel 1 dan 2 .

Tabel 1. Formula pewarna rambut permanen

\begin{tabular}{clcccccc}
\hline \multirow{2}{*}{ No } & \multirow{2}{*}{ Nama Bahan } & \multicolumn{7}{c}{ Formula } \\
\cline { 2 - 7 } & & F0 & F1 & F2 & F3 & F4 & F5 \\
\hline 1 & Ekstrak kental daun ketapang & 0 & 0 & 12,5 & $\mathbf{1 0}$ & 12,5 & 15 \\
2 & Ekstrak kental daun jambu biji & 0 & 12,5 & $\mathbf{0}$ & 12,5 & 12,5 & 12,5 \\
3 & Carbomer & 2 & 2 & 2 & 2 & 2 & 2 \\
4 & Sodium lauryl sulfat & 25 & 25 & 25 & 25 & 25 & 25 \\
5 & Cocamide DEA & 3 & 3 & 3 & 3 & 3 & 3 \\
6 & Sodium sulfit & 0,3 & 0,3 & 0,3 & 0,3 & 0,3 & 0,3 \\
7 & EDTA 2 Na & 0,05 & 0,05 & 0,05 & 0,05 & 0,05 & 0,05 \\
8 & Phenoxyethanol & 0,2 & 0,2 & 0,2 & 0,2 & 0,2 & 0,2 \\
9 & Ammonium hidroksida 20\% & 10 & 10 & 10 & 10 & 10 & 10 \\
10 & Purified water Ad & 100 & 100 & 100 & 100 & 100 & 100 \\
\hline
\end{tabular}

Keterangan: $\mathrm{FO}=$ formula krim tanpa ekstrak daun ketapang dan ekstrak daun jambu biji (kontrol negatif); F1=formula krim dengan ekstrak tunggal jambu biji 12,5\%; F2=formula krim dengan ekstrak tunggal daun ketapang $12,5 \%$; $F 3=$ formula krim dengan ekstrak daun ketapang $10 \%$ dan ekstrak jambu biji 12,5\%. F4=formula krim dengan ekstrak daun ketapang 12,5\% dan ekstrak jambu biji 12,5\%; F5=formula krim dengan ekstrak daun ketapang 15\% dan ekstrak jambu biji $12,5 \%$.

5. Pembuatan krim basis developer

Setil alkohol, emulgide 1000NI dilelehkan di atas waterbath suhu 70 ${ }^{\circ} \mathrm{C}$ (fase minyak), dilarutkan dalam purified water sebanyak $50 \mathrm{ml}$. Disodium EDTA, sodium pirophosfate, phenoxy ethanol dipanaskan di atas waterbath suhu 70
${ }^{\circ} \mathrm{C}$ (fase air), dicampur fase minyak ke dalam fase air, diaduk homogen. Krim didinginkan sampai suhu $\pm 40^{\circ} \mathrm{C}$, ditambahkan hidrogen peroksida, diaduk homogen, digenapkan massa sampai 100 gram, diaduk homogen. Formula pewarna rambut dapat dilihat pada Tabel 1 dan 2 . 
Vol.16 No. 02 Desember 2019:356-371

Tabel 2. Formula krim basis developer

\begin{tabular}{clcccccc}
\hline \multirow{2}{*}{ No } & \multirow{2}{*}{ Nama Bahan } & Formula \\
\cline { 3 - 8 } & & F0 & F1 & F2 & F3 & F4 & F5 \\
\hline 1 & Setyl alkohol & 5 & 2 & 2 & 2 & 2 & 2 \\
2 & Glyceril monostearate & 5 & 5 & 5 & 5 & 5 \\
3 & Sodium pirophosfate & 0,01 & 0,01 & 0,01 & 0,01 & 0,01 & 0,01 \\
4 & Phenoxyethanol & 0,2 & 0,2 & 0,2 & 0,2 & 0,2 & 0,2 \\
5 & Hidrogen peroksida 30\% & 20 & 20 & 20 & 20 & 20 & 20 \\
6 & EDTA 2 Na & 0,05 & 0,05 & 0,05 & 0,05 & 0,05 & 0,05 \\
7 & Phosporic acid & 1 & 1 & 1 & 1 & 1 & 1 \\
8 & Purified water ad & 100 & 100 & 100 & 100 & 100 & 100 \\
\hline
\end{tabular}

6. Evaluasi krim

Sediaan yang dihasilkan dievaluasi meliputi pemeriksaan organoleptik, homogenitas, $\mathrm{pH}$ dan viskositas, Selain itu pada sediaan krim dilakukan uji aktivitas pewarna.

\section{Hasil dan Pembahasan}

Hasil pemeriksaan mutu ekstrak daun ketapang dan ekstrak daun jambu biji menunjukkan bahwa ekstrak yang dihasilkan memenuhi syarat mutu ekstrak yang baik. Hasil pemeriksaan mutu dapat dilihat pada Tabel 3. Hasil penetapan kadar abu total pada ekstrak daun ketapang dan ekstrak daun jambu biji memberikan gambaran kandungan mineral internal maupun eksternal baik senyawa organik maupun anorganik yang memenuhi syarat ekstrak yang baik. Kadar abu total menunjukkan total mineral dalam suatu bahan tanaman. Hasil pengujian kadar abu tak larut asam, memenuhi syarat, karena kadar menunjukkan persentase yang rendah untuk ekstrak daun ketapang dan ekstrak daun jambu biji di mana persentase kadar abu tak larut asam yang tinggi menunjukkan adanya kontaminasi mineral yang tidak larut dalam asam, seperti pasir atau tanah silikat serta pengotor lain, dengan demikian ekstrak yang dibuat telah memenuhi syarat mutu ekstrak yang baik dan dapat digunakan sebagai bahan baku sediaan krim. Pengujian kadar abu dimaksudkan untuk melihat kandungan logam berat yang terkandung. Hasil uji kadar air menunjukkan kedua ekstrak memenuhi syarat ekstrak yaitu kurang atau tidak boleh lebih dari 10\%. Kadar air yang tinggi pada ekstrak dapat mempengaruhi kualitas ekstrak bila penyimpanan terlalu lama, akan mempermudah mikroorganisme tumbuh di ekstrak tersebut. Hasil dari uji mutu ekstrak tersebut menunjukkan bahwa ekstrak dapat digunakan sebagai bahan baku dalam formulasi sediaan krim pewarna rambut (Depkes RI, 2008; Depkes RI, 1989). 
Tabel 3. Hasil uji mutu ekstrak daun ketapang (Terminalia catappa L) dan ekstrak daun jambu biji (Psidium Guajava L.)

\begin{tabular}{clccc}
\hline \multirow{2}{*}{ No } & \multirow{2}{*}{ Parameter } & \multicolumn{2}{c}{ Hasil (\%) } & \multirow{2}{*}{$\begin{array}{c}\text { Syarat MMI } \\
\text { (\%) }\end{array}$} \\
\cline { 3 - 4 } & & EDK & EDJB & \\
\hline 1 & Kadar Air & 8,17 & 7,910 & $<8,88-\mathbf{1 0}$ \\
2 & Kadar abu total & 2,70 & 3,49 & $<15,07$ \\
3 & Kadar abu tidak larut asam & 0,18 & 0,20 & $<4,5-11,09$ \\
4 & Kadar sari larut air & 35,08 & 19,68 & $>14,5-19,00$ \\
5 & Kadar sari larut etanol & 22,02 & 31,71 & $>18-19,00$ \\
\hline
\end{tabular}

Keterangan: EDK=ekstrak daun ketapang; EDJB=ekstrak daun jambu biji.

Hasil pemeriksaan penapisan Tannin dan fenol dapat memberikan fitokima ekstrak dapat dilihat pada Tabel warna coklat jika teroksidasi. Ini 4. Hasil menunjukkan bahwa kandungan menunjukkan bahwa hasil pemeriksaan metabolit sekunder yang terdapat dalam menunjukkan hasil yang sama dengan ekstrak daun ketapang adalah flavonoid, literatur, dengan demikian dapat saponin, tannin, kumarin, dan fenol. digunakan sebagai bahan pewarna Sedangkan ekstrak daun jambu biji dalam sediaan pewarna rambut (Shruthi mengandung steroid, terpenoid, et al., 2013; Depkes RI, 2000; Depkes RI, flavonoid, kuinon, tannin, dan fenol. 2008; Depkes RI, 1989).

Tabel 4. Hasil penapisan fitokimia ekstrak daun ketapang (Terminalia catappa $\mathrm{L}$ ) dan ekstrak daun jambu biji (Psidium guajava L.)

\begin{tabular}{clcc}
\hline No & Ekstrak & Pengujian & Hasil Uji \\
\hline 1 & Ekstrak daun ketapang & Alkaloid & - \\
& & Steroid & - \\
& Terpenoid & - \\
& Flavonoid & + \\
& Saponin & + \\
& Kuinon & - \\
& Tanin & + \\
& Kumarin & + \\
& Ekstrak daun jambu biji & Fenolik & + \\
& Slkaloid & - \\
& Steroid & + \\
& Terpenoid & + \\
& Flavonoid & + \\
& Saponin & + \\
& Kuinon & + \\
& Tanin & + \\
& & Kumarin & + \\
& & Fenolik & \\
& & & + \\
& & &
\end{tabular}

Keterangan: $(+)=$ ada kandungan metabolit sekunder; $(-)=$ tidak ada kandungan metabolit sekunder. 
Hasil pengujian aktivitas menghasilkan warna coklat yang lebih
pewarna tunggal dengan lama kuat. perendaman 60 menit menunjukkan bahwa ekstrak daun jambu biji tunggal memberikan rata-rata warna merah dengan nilai a 8,16 dan warna biru dengan nilai b 13,03 . Ekstrak tunggal daun ketapang memberikan rata-rata warna merah dengan nilai a 6,75 dan warna biru dengan nilai b 15,45 . Warna merah dari ekstrak jambu biji tunggal lebih besar dibanding warna merah ekstrak daun ketapang tunggal. Warna biru ekstrak daun ketapang lebih besar dari warna biru ekstrak daun jambu biji. Hasil uji warna ekstrak tunggal dapat dilihat pada Tabel 5. Perpaduan warna merah dari ekstrak daun jambu biji dengan warna biru dari ekstrak daun ketapang diharapkan dapat
Hasil evaluasi organoleptis dan uji $\mathrm{pH}$ sediaan krim dapat dilihat pada Tabel 6. Hasil pengamatan organoleptis meliputi bentuk sediaan, warna, dan bau. Uji $\mathrm{pH}$ sediaan krim developer diperoleh $\mathrm{pH}$ 3,00; $\mathrm{pH}$ sediaan krim pewarna diperoleh $\mathrm{pH} 12,00$; dan $\mathrm{pH}$ campuran krim developer dan krim pewarna yaitu $\mathrm{pH} 8,00$ sehingga sediaan tersebut berfungsi membantu terbukanya kutikula rambut sehingga rambut lebih mudah diwarnai. Hasil menunjukkan bahwa sediaan berada pada batas persyaratan $\mathrm{pH}$ yang diizinkan untuk pewarna rambut yaitu 712 dan tidak mengiritasi kulit (de Oliveira et al., 2014; Depkes RI, 1995).

Tabel 5. Hasil uji warna terhadap formula yang mengandung ekstrak tunggal daun jambu biji dan daun ketapang

\begin{tabular}{lll}
\hline \multicolumn{3}{c}{60 menit 1x cuci } \\
\hline F0 & \multicolumn{1}{c}{ F1 } & F2 \\
& \\
& \\
& \\
& & \\
Nilai Rata-rata: & & \\
$a=+4,78$ & $a=+8,16$ & \\
$b=-12,82$ & $b=-13,03$ & $a=+6,75$ \\
$L=+50,91$ & $L=+40,82$ & $b=-15,45$ \\
& & $L=+39,15$
\end{tabular}

Keterangan: $a=0-(-60)$ memberikan warna hijau dan 0-60 memberikan warna merah; $b=0-(-$ 60) memberikan warna biru dan $0-60$ memberikan warna kuning; $L=0-(-100)$ memberikan warna putih dan 0 - 100 Memberikan warna hitam; F0=basis (kontrol negatif); F1=ekstrak daun jambu biji 12,5\%; F2=ekstrak daun ketapang $12,5 \%$. 
Tabel 6. Hasil uji sediaan krim pewarna rambut secara organoleptis

\begin{tabular}{ccccccc}
\hline No. & $\begin{array}{c}\text { Formula } \\
\text { Krim Pewarna }\end{array}$ & Warna & Bentuk & Bau & Homogenitas & pH \\
\hline 1 & F0 & Putih & Krim & Amoniak & Homogen & 12,00 \\
2 & F1 & Coklat muda & Krim & Amoniak & Homogen & 12,00 \\
3 & F2 & Coklat muda & Krim & Amoniak & Homogen & 12,00 \\
4 & F3 & Coklat muda & Krim & Amoniak & Homogen & 12,00 \\
5 & F4 & Coklat muda & Krim & Amoniak & Homogen & 12,00 \\
6 & F5 & Coklat muda & Krim & Amoniak & Homogen & 12,00 \\
7 & Krim developer & Putih & Krim & Tidak berbau & Homogen & 3,00 \\
8 & Krim campuran & Coklat muda & Krim & Amoniak & Homogen & 8,00 \\
\hline
\end{tabular}

Keterangan: $\mathrm{FO}=$ basis (kontrol negatif); $\mathrm{F} 1=$ ekstrak daun jambu biji 12,5\%; F2=ekstrak daun ketapang 12,5\%; F3=kombinasi ekstrak daun jambu biji 12,5\% dan ekstrak daun ketapang 10\%; F4=kombinasi ekstrak daun jambu biji 12,5\% dan ekstrak daun ketapang 12,5\%; F5=kombinasi ekstrak daun jambu biji 12,5\% dan ekstrak daun ketapang 15\%; krim campur (1:1)=campuran pewarna dengan developer.

Hasil pengujian aktivitas ekstrak kombinasi dapat dilihat pada Tabel 6 . Warna merah dengan nilai a F5 $(7,36)$ lebih besar dari $F 4(7,35)$ lebih besar dari F3 $(7,12)$. Warna biru dengan nilai b F5 $(16,96)$ lebih besar dari F4 $(16,51)$ lebih besar dari F3 $(16,40)$ artinya setelah dikombinasi warna biru naik dari awal ekstrak tunggal yaitu: 13,03 (F1 daun jambu biji) dan 15,45 (F2 daun ketapang). Warna coklat yang dipantulkan adalah coklat muda maka untuk memperkuat intensitas warna coklat, lama perendaman menjadi 2 jam.

Hasil warna setelah direndam selama 2 jam yaitu warna merah dengan nilai a F5 $(8,10)$ lebih besar dari F4 $(7,79)$ lebih besar dari F3 $(7,69)$, warna biru dengan nilai b F5 $(17,21)$ lebih besar dari F4 $(16,91)$ lebih besar dari F3 $(16,81)$. Terjadi peningkatan warna merah dan warna biru, tetapi secara visual warna coklat dengan perendaman 60 dan 120 menit perbedaannya tidak terlalu mencolok dan aplikasi yang terlalu lama
(Tabel 7). Formula F5 merupakan formula yang optimal karena waktu aplikasi yang lebih singkat dan warna biru dan merah yang lebih kuat dibanding F3 dan F4 (de Oliveira et al., 2014; Depkes RI, 1995).

Secara visual warna rambut F5 yang dihasilkan oleh kombinasi ekstrak daun ketapang dan ekstrak daun Jambu biji masih berwarna coklat muda (Tabel 6). Intensitas warna coklat dapat ditingkatkan dengan menambahkan logam. Untuk meningkatkan warna rambut dapat juga dengan cara menambahkan logam sebagai pembangkit warna. Adapun garamgaram logam yang bisa digunakan sebagai pembangkit warna seperti: ferri klorida $\left(\mathrm{Fe}^{3+}\right)$ dan tembaga sulfat $\left(\mathrm{Cu}^{2+}\right)$. Penambahan logam dilakukan terhadap F5 karena merupakan formula yang optimal memberikan warna merah dengan nilai a $(7,36)$ dan warna biru dengan nilai $b(16,96)$ dengam lama perendaman 60 menit. 
Tabel 7. Hasil uji warna terhadap formula ekstrak daun jambu biji dengan variasi konsentrasi ekstrak daun ketapang

\begin{tabular}{|c|c|c|c|c|c|c|}
\hline \multirow[t]{2}{*}{ FO } & \multicolumn{2}{|c|}{ F3 } & \multicolumn{2}{|c|}{ F4 } & \multicolumn{2}{|c|}{ F5 } \\
\hline & $\begin{array}{c}60 \text { menit } \\
1 \times \text { cuci }\end{array}$ & $\begin{array}{l}120 \text { menit } \\
1 \times \text { cuci }\end{array}$ & $\begin{array}{c}60 \text { menit } \\
1 \times \text { cuci }\end{array}$ & $\begin{array}{l}120 \text { menit } \\
1 \times \text { cuci }\end{array}$ & $\begin{array}{c}60 \text { menit } \\
1 \times \text { cuci }\end{array}$ & $\begin{array}{l}120 \text { menit } \\
1 \times \text { cuci }\end{array}$ \\
\hline 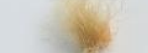 & & & & & & \\
\hline Nilai rata- & & & & & & \\
\hline$a=+4,78$ & $a=+7,12$ & $a=+7,69$ & $a=+7,35$ & $a=+7,79$ & $a=+7,36$ & $a=+8,10$ \\
\hline$b=-12,82$ & $b=-6,40$ & $b=-16,81$ & $b=-16,51$ & $b=-16,91$ & $b=-16,96$ & $b=-17,21$ \\
\hline $\mathrm{L}=+50,91$ & $\mathrm{~L}=+40,49$ & $\mathrm{~L}=+41,31$ & $\mathrm{~L}=+40,56$ & $\mathrm{~L}=+41,40$ & $\mathrm{~L}=+44,66$ & $\mathrm{~L}=+41,54$ \\
\hline
\end{tabular}

Keterangan: $\mathrm{L}=0-(-100)$ memberikan warna putih dan 0-100 memberikan warna hitam; $\mathrm{a}=0-(-60)$ memberikan warna hijau dan $0-60$ memberikan warna merah; $b=0-(-60)$ memberikan warna

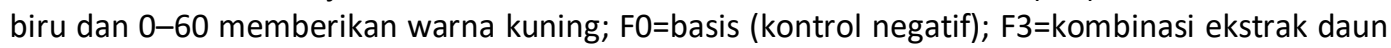
jambu biji 12,5\% dan ekstrak daun ketapang 10\%; F4 =kombinasi ekstrak daun jambu biji 12,5\% dan ekstrak daun ketapang 12,5\%; F5=kombinasi ekstrak daun jambu biji 12,5\% dan ekstrak daun ketapang $15 \%$.

Tabel 8. Hasil uji warna terhadap formula F5 dengan penambahan logam

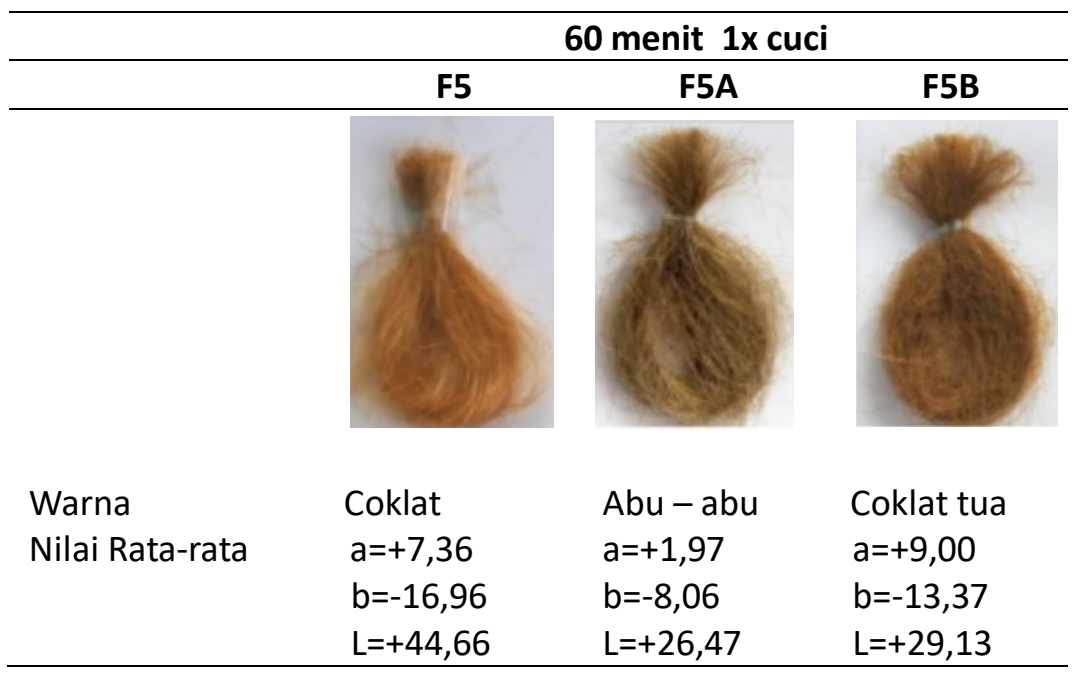

Keterangan: F5=kombinasi ekstrak daun jambu biji 12,5\% dan ekstrak daun ketapang 15\% tanpa logam; F5A=kombinasi ekstrak daun jambu biji 12,5\% dan ekstrak daun ketapang $15 \%$ dengan penambahan ferri klorida $1 \%$; F5B=kombinasi ekstrak daun jambu biji 12,5\% dan ekstrak daun ketapang $15 \%$ dengan penambahan tembaga sulfat $1 \%$. 
Hasil uji warna dengan penambahan logam feri klorida $1 \%$ memberikan rata-rata warna merah dengan nilai a $(1,97)$ dan warna biru dengan nilai $b(8,06)$ artinya komposisi warna merah semakin kecil dibanding warna biru dan lebih dominan nilai L $(26,47)$ yang mengarah ke warna hitam sehingga warna yang terpantul adalah Abu-abu. Sedangkan dengan penambahan logam tembaga sulfat $1 \%$ rata-rata warna merah dengan nilai a $(9,00)$ dan rata-rata warna biru dengan nilai b $(13,37)$ memberikan warna merah dan biru yang lebih tinggi dibanding dengan penambahan logam feri klorida, sehingga warna yang dipantulkan adalah coklat tua. Gambar dapat dilihat pada Tabel 8. Formula F5B memberikan warna coklat tua dengan rata-rata warna merah dengan nilai a yang tertinggi yaitu 9,00 merupakan formula yang optimal. Maka dapat dilakukan uji lanjut yaitu uji daya lekat pewarna rambut dengan pencucian sebanyak 7x. Hasil pencucian dapat dilihat pada Tabel 9.

Tabel 9. Hasil uji daya lekat pewarna rambut F5B

\begin{tabular}{lll}
\hline Nama sampel & \multicolumn{2}{c}{60 menit } \\
\hline F5B & $1 \times$ cuci & 7x cuci \\
& & \\
& & \\
& & \\
Warna & Coklat tua & Coklat tua \\
Nilai Rata-rata & $a=+9,00$ & $a=+8,99$ \\
& $b=-13,37$ & $b=-13,35$ \\
& $L=+29,13$ & $L=+29,11$ \\
\hline
\end{tabular}

Keterangan: $\mathrm{F} 5 \mathrm{~B}=$ kombinasi ekstrak daun jambu biji 12,5\% dan ekstrak daun ketapang $15 \%$ dengan penambahan tembaga sulfat $1 \%$.

Data pada Tabel 9 menunjukkan bahwa warna merah dengan 1 kali pencucian dan $7 x$ pencucian hampir sama yaitu 9,00 dan 8,99 , dan warna biru dengan 1 kali pencucian dan 7 kali pencucian yaitu 13,37 dan 13,35 Selisih nilai a (merah) dan b (biru) dengan 1 kali pencucian dan 7 kali pencucian tidak terlalu besar, sehingga dapat dikatakan
F5B merupakan pewarna rambut Permanen.

Dengan data statistik dapat dibandingkan apakah 1 kali pencucian dan 7 kali pencucian perbedaannya bermakna atau tidak. Uji normalitas (Kolgomorov-Smirnov) menunjukkan nilai $p>0,05$ berarti data terdistribusi normal dan homogen untuk warna 
merah dan tidak homogen untuk warna biru, uji Mann-Whitney $p>0,05$ berarti tidak terdapat perbedaan yang bermakna dari pencucian 1 kali dan 7 kali. Maka F5B dapat dikatakan permanen.

Tabel 10. Evaluasi F5B setelah dicampur krim developer

\begin{tabular}{lcc}
\hline Parameter & Spesifikasi & Hasil \\
\hline Organoleptis & & \\
- Bentuk & Krim & sesuai \\
- Warna & Coklat tua & sesuai \\
- Bau & khas amoniak & sesuai \\
$\mathrm{pH}$ & $7-12$ & 8,00 \\
Berat jenis & $0,900-1,100 \mathrm{~g} / \mathrm{ml}$ & $1,0007 \mathrm{~g} / \mathrm{ml}$ \\
Viskositas & $10.000-20.000 \mathrm{cps}$ & $12.500 \mathrm{cps}$ \\
\hline
\end{tabular}

Keterangan: F5B=kombinasi ekstrak daun jambu biji 12,5\% dan ekstrak daun ketapang $15 \%$ dengan penambahan tembaga sulfat $1 \%$.

Tabel 11. Perbandingan warna formula F5, F5B, dan produk pesaing (Miranda PHC (MC-9 Brown)

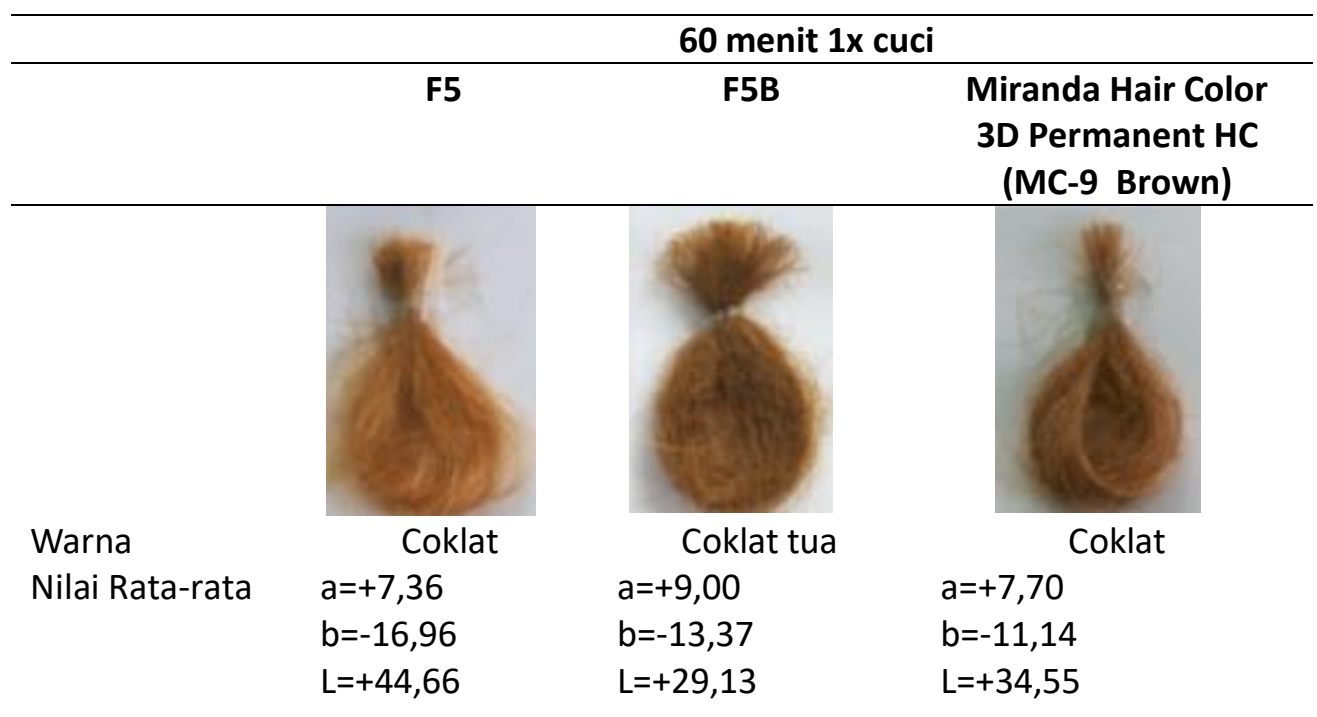

Keterangan: F5=kombinasi ekstrak daun jambu biji 12,5\% dan ekstrak daun ketapang 15\% tanpa logam; F5A=kombinasi ekstrak daun jambu biji 12,5\% dan ekstrak daun ketapang 15\% dengan penambahan feri klorida 1\%; produk pesaing=Miranda hair color 3D permanent HC (MC-9 Brown).

Setelah dicampur krim pewarna rambut, nilai $\mathrm{pH}$ adalah 8 dan kekentalan 12.500 cps. Pada saat diaplikasi krim pewarna rambut, mudah diaplikasikan karena kekentalannya tidak terlalu tinggi. Bau amoniak masih tercium tetapi tidak terlalu menyengat. Warna yang dihasilkan 5B ini adalah coklat tua. 
Dari Tabel 11 diperoleh data rata-rata warna merah dengan nilai a F5B $(9,00)$ lebih tinggi dibandingkan dengan rata-rata warna merah dengan nilai a F5 $(7,36)$ dan rata-rata warna merah dengan nilai a produk pesaing $(7,70)$, artinya formula dengan penambahan logam tembaga sulfat mempunyai jumlah warna merah yang lebih banyak dan warna rambut menjadi lebih coklat. Kalau dirasiokan nilai L,a,b $\mathrm{F} 5=(6,06: 1: 2,30)$

$\mathrm{F} 5 \mathrm{~B}=(3,23: 1: 1,48)$ produk pesaing Miranda
PHC $=(4,48: 1: 1,44)$. Jadi penambahan logam pada F5B menyebabkan berkurangnya warna biru yang mempengaruhi warna merah semakin besar dan warna semakin merah. Secara statistik uji normalitas (KolgomorovSmirnov) $\mathrm{p}>0,05$ data terdistribusi normal dan uji homogenitas (Levene) $p>0,05$ data terdistribusi homogen. Uji Mann-Whitney $p<0,05$ berarti terdapat perbedaan warna yang bermakna pada F5, F5B terdapat produk pesaing.

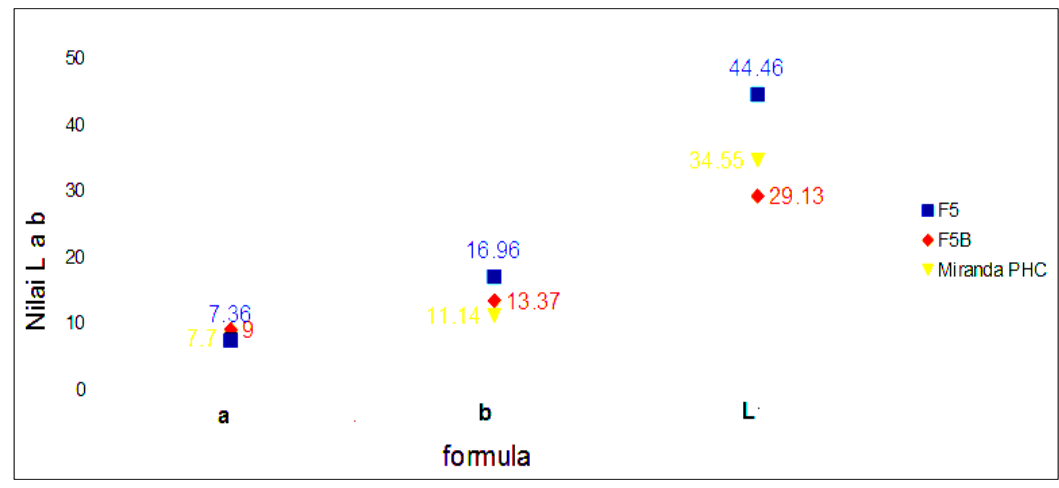

Gambar 1. Grafik F5 VS F5B VS Miranda PHC.

\section{Simpulan}

Telah dibuat krim pewarna rambut permanen yang mengandung kombinasi ekstrak daun ketapang 15\% dan daun jambu biji 2,5\% sebagai pewarna rambut permanen. Diperoleh masing-masing ekstrak memiliki aktivitas sebagai pewarna rambut uban/putih rata-rata warna merah ekstrak daun jambu biji dengan nilai a $(8,16)$ dan warna biru dengan nilai b $(13,03)$ dan ekstrak daun ketapang memberikan rata-rata warna merah dengan nilai a
$(6,75)$ dan warna biru dengan nilai b $(15,45)$. Krim pewarna rambut yang mengandung kombinasi ekstrak daun ketapang 15\% dan ekstrak daun jambu biji 12,5\% memenuhi syarat sebagai krim pewarna rambut karena secara organoleptis berbentuk kental dengan warna coklat dan berbau khas, $\mathrm{pH}$ 8-10, viskositas $12.500 \mathrm{cps}$, bj 1,0007 g/ml. Memberikan efek warna merah yang optimal dengan nilai a $(7,36)$ dan warna biru dengan nilai b $(16,96)$. Krim pewarna rambut mengandung 
kombinasi ekstrak ketapang 15\% dan ekstrak daun daun jambu biji 12,5\% tidak menunjukkan gejala iritasi dengan nilai indek iritasi 0 (nol) baik terhadap masing-masing ekstrak tunggal, ekstrak kombinasi, kontrol negatif, basis krim dan krim pewarna rambut. Krim pewarna rambut dengan kombinasi ekstrak daun ketapang 15\% dan ekstrak daun jambu biji $12,5 \%$ (F5) dengan penambahan logam tembaga sulfat $1 \%$ memberikan warna terbaik sebagai pewarna rambut permanen. Warna merah 1 kali pencucian dengan nilai a $(9,00)$ dan 7 kali pencucian $(8,99)$. Hasil uji statistik Mann-Whitney Asymp Sig 0,197; $p>0,05$ berarti tidak terdapat perbedaan yang bermakna dari pencucian 1 kali dan 7 kali.

\section{Daftar Pustaka}

Thomson, L.A.J. and Evans, B. 2006. Terminalia catappa (tropical almond). Ver. 2.2. in Species Profiles for Pacific Island Agroforestry. Elevitch, C.R. (Ed.). Hawaii: Permanent Agriculture Resources (PAR).

Dr.Duke's Phytochemical and Ethnobotanical Database: List of All Chemicals P Terminalia catappa (Combretaceae). 1992. http://phytochem.nal.usda.gov/. Data diakses pada 2 Juli 2019.

Satyanand, T., Ajeet, S., Poonam, B., Sandeep, S., Yada, A.P. 2012. Punicalagins-a large polyphenol compounds found in pomegranates: A Therapeutic Review. Academic Journal of Plant Sciences, 5(2):45-49.
Chansue, N., Assawawongkasem, N. 2008. The in vitro antibacterial activity and ornamental fish toxicity of the water extract of indian almond leaves (Terminalia catappa Linn.). KKU Veterinary Journal, 18(1):36-45.

Depkes RI. 1995. Farmakope Indonesia. Edisi IV. Jakarta: Departemen Kesehatan Direktorat Jenderal Pengawasan Obat dan Makanan.

Depkes RI. 2000. Parameter Standar Umum Ekstrak Tumbuhan Obat. Jakarta: Departemen Kesehatan RI.

Shruthi, S.D., Roshan, A., Sharma, S., Sunita, S. 2013. A review on the medicinal plant Psidium guajava Linn (Myrtaceae). Journal of Drug Delivery and Therapeutics, 3(2):162-168.

Depkes RI. 2008. Farmakope Herbal Indonesia. Jakarta: Badan Pengawas Obat dan Makanan.

Depkes RI. 1989. Materia Medika. Jilid V. Jakarta: Departemen Kesehatan RI.

de Oliveira, R.A.G., Zanoni, T.B., Bessegato, G.G.B., Oliveira, D.P., Umbuzeiro, G.A., Valnice, M., Zanoni, B. 2014. The chemistry and toxicity of hair dyes. Quim Nova, 37(6):1037-1046. 